\title{
TITANYL SULPHATE, AN INORGANIC POLYMER: STRUCTURAL STUDIES AND VIBRATIONAL ASSIGNMENT
}

Lucia Kiyomi Noda $^{\mathrm{a}, *,(\mathbb{D}}$, Fabricio Ronil Sensato ${ }^{\mathrm{a}}$ and Norberto Sanches Gonçalves ${ }^{\mathrm{a}}$

anstituto de Ciências Ambientais, Químicas e Farmacêuticas, Departamento de Química, Universidade Federal de São Paulo, Campus Diadema, 09972-270 Diadema - SP, Brasil

Recebido em 08/06/2019; aceito em 02/08/2019; publicado na web em 21/10/2019

\begin{abstract}
In this work, anhydrous titanyl sulfate $\left(\mathrm{TiOSO}_{4}\right)$ was synthesized and characterized by elemental analyses and vibrational spectroscopy by the first time. In order to verify the stability of the crystallographic structure reported in the literature, an optimization calculation of the unit cell geometry was done with the CRYSTAL17 software, and the agreement with the experimental results was very good. Raman, infrared and far infrared spectra were obtained, the bands having been tentatively assigned, based on literature data for similar systems. Essentially, the spectra exhibit the vibrational modes of the sulfate anion splitted by the low local symmetry along with the bands of the $\mathrm{TiO}_{6}$ skeleton. The Raman spectra shows two intense bands, tentatively assigned to Ti-O modes.
\end{abstract}

Keywords: titanyl sulfate; Raman spectroscopy; infrared spectroscopy; solid state ab initio calculation; CRYSTAL17.

\section{INTRODUCTION}

Titanyl sulfate, both in its anhydrous and hydrated form, is an interesting substance from the structural point of view due to its three-dimensional polymer structure and also from the technological standpoint. $\mathrm{TiOSO}_{4}$ is also a source of obtaining the sulfated titanium dioxide, an important catalyst in the field of Heterogeneous Catalysis. One of the ways of obtaining $\mathrm{TiOSO}_{4}$ consists in the dissolution of the ilmenite $\left(\mathrm{FeTiO}_{3}\right)$ by concentrated $\mathrm{H}_{2} \mathrm{SO}_{4}$, yelding intermediately a solution of $\mathrm{TiO}_{2}$ and ferrous sulfate. $\mathrm{TiO}_{2}$ is obtained by hydrolysis, giving rise to hydrated $\mathrm{TiO}_{2}$, which is separated from the solution containing $\mathrm{Fe}(\mathrm{II})$. The anhydrous form of $\mathrm{TiO}_{2}$ is obtained by heat treatment of the hydrated form, according to Hadjiivanov and Klissurski. ${ }^{1}$ Due to the fact that the precursor $\mathrm{TiOSO}_{4}$ already contains sulfate, it is also possible to obtain sulphated titanium oxide by this route, which, being superacid, allows the formation of intermediate species on its surface, which can be studied by electronic and vibrational spectroscopy. ${ }^{2,3}$

The titanyl ion, with $\mathrm{Ti}=\mathrm{O}$ double bond, is hardly found in compounds containing this ion in the solid state, according to Grätzel and Rotzinger. ${ }^{4}$ They cited as examples, the complexes TiO(porphyrin), ${ }^{5} \mathrm{TiO}$ (phtalocyanine), ${ }^{6,7}\left(\mathrm{R}_{4} \mathrm{~N}\right){ }_{2} \mathrm{TiCl}_{4} \mathrm{O},{ }^{8} \mathrm{TiO}($ edtaH 2$)$ $\left(\mathrm{H}_{2} \mathrm{O}\right)^{9}$ and $\left[\mathrm{TiOF}_{5}\right]^{3-},{ }^{10}$ the latter presenting $v(\mathrm{Ti}=\mathrm{O})$ wavenumber at ca. $950 \mathrm{~cm}^{-1}$. Some titanyl compounds in aqueous solution have the $\mathrm{Ti}=\mathrm{O}$ bond, for example, $\mathrm{TiO}\left(\mathrm{ClO}_{4}\right)_{2}$ in acid medium, with a weak band at $975 \mathrm{~cm}^{-1}$ assigned to $\mathrm{Ti}=\mathrm{O}$ stretching. ${ }^{4,11}$ However, the predominant species are oligomers or protonated species, in which the bonding order is lower. ${ }^{4}$ Titanyl sulfate in the solid state has a polymer chain -Ti-O-Ti-O-Ti-O-, also observed in compounds $\mathrm{TiOX}_{2}$ $(\mathrm{X}=\mathrm{F}, \mathrm{Cl}, \mathrm{Br}, \mathrm{I}) .{ }^{12} \mathrm{X}$-ray diffractograms of $\mathrm{TiOSO}_{4}$ have provided the most realistic structure, in which the titanium is hexacoordinated. ${ }^{13}$

As will be shown below, the structure presents Ti-O(4)- zigzag chains with short Ti-O(4) bonds, connected by sulfate groups $(2 \mathrm{O}(1)$, $\mathrm{O}(2)$ and $\mathrm{O}(3)$ ), the corresponding Ti-O bonds are longer than the Ti-O bonds of the chain. Two possible symmetries were proposed for the space group, Pnma or Pna $2_{1}$. Although there are infrared absorption spectroscopy data for the monohydrate and the dihydrate, ${ }^{14}$ the literature does not report characterization studies of solid anhydrous

*e-mail: lucia.noda@unifesp.br
$\mathrm{TiOSO}_{4}$ by Raman or infrared vibration spectroscopy, which is the main objective of this work.

\section{EXPERIMENTAL}

\section{Syntheses}

Anhydrous titanyl sulfate $\left(\mathrm{TiOSO}_{4}\right)$ was prepared according to the method described by Kjekshus et al. ${ }^{13}$ in which $1.6 \mathrm{~g}$ of $\mathrm{TiO}_{2}$ (TIBRAS) is refluxed with $20 \mathrm{~mL}$ of concentrated $\mathrm{H}_{2} \mathrm{SO}_{4}$ (LabSynth) under magnetic stirring for four hours in a $50 \mathrm{~mL}$ flask with condenser. At first it is observed dissolution of the $\mathrm{TiO}_{2}$, giving rise to a light yellow solution, which slowly becomes cloudy. After cooling, the precipitate is filtered in sintered glass, followed by washing with glacial acetic acid and ethyl ether, followed by drying in vacuum. The material obtained is in the form of a white powder. The sulfur content obtained for $\mathrm{TiOSO}_{4}$ was $20.50 \%$ (expected $=20.01 \%$ ).

\section{Spectroscopic methods}

Infrared absorption spectra were obtained employing the $\mathrm{KBr}$ pellet method. $\mathrm{KBr}$ was spectroscopic grade from clived windows to assure minimum water content. It was also possible to use absorption spectroscopy in the far infrared region, with the sample dispersed in mineral oil between HDPE plates. The equipments used were a Shimadzu FTIR Prestige-21 fitted with DTGS/KBr detector and Ge@ $\mathrm{KBr}$ beamsplitter for the mid infrared region and a Bomem DA3.16, equipped with globar source, DTGS detector with polyethylene windows and Mylar 3 micra beamsplitter. With these assemblies regions of 4000 to $400 \mathrm{~cm}^{-1}$ and from 400 to $100 \mathrm{~cm}^{-1}$ were recorded. Raman spectra were recorded on a Renishaw InVia, with the line at $632.8 \mathrm{~nm}$ of the He-Ne laser. Laser power was adjusted to $1.5 \mathrm{~mW}$. The sample was placed in a slide glass and slightly pressed. This sample was left in the air for three days and the spectrum was repeated; reproducibility was verified, which demonstrated the stability of the sample against humidity. Spectral resolution was set to $4 \mathrm{~cm}^{-1}$ for all spectra.

\section{Computational methods}

Our work was supplemented by electronic structure calculations 
at DFT level, which were performed using the computer code CRYSTAL17. ${ }^{15}$ For the exchange-correlation (XC) potential it was applied the revised PBE generalized gradient approximation for solids, PBEsol. ${ }^{16}$ CRYSTAL17 uses a local Gaussian basis set, as opposite to the plane waves that are the most common choice in quantum programs devoted to the solid state. In this work, all-electron basis sets have been employed in the calculations with 86-41131 (one $\mathrm{s}$, four $s p$ and $2 d$ shell) ${ }^{17} 86-311111$ (one $s$, five $s p$ and two $d$ shell) ${ }^{18}$ and 8-4111 (one $s$, three $s p$ and one $d$ shell) ${ }^{19}$ contractions for titanium, sulfur and oxygen atoms, respectively. All of them are available via the online library of the code. ${ }^{20}$ We employed a Monkhorst-Pack shrinking factor of 8 for reciprocal space sampling. The calculations were conducted using Coulombic and exchange integral tolerance factors of 6, 6, 6, 6 and 12 (TOLINTEG) and the accuracy on the SCF convergence (TOLDEE) was set to 10 . The crystal structure has been optimized by minimizing the total energy with respect to the lattice parameters and the position of atoms in the unit cell.

\section{RESULTS AND DISCUSSION}

\section{Computational Methods}

In particular, the crystallographic structure of $\mathrm{TiOSO}_{4}$ is orthorhombic with the space group Pnma, number 62 in the standard listing. The primitive cell contains four $\mathrm{TiOSO}_{4}$ formula units, $\mathrm{Z}=4$. Yet, there are five non-equivalent atoms in the corresponding asymmetric unit, namely, Ti, S, O(1), O(2), O(3) and $\mathrm{O}(4) \cdot{ }^{13} \mathrm{~A}$ Moldraw ${ }^{21,22}$ representation of the $\mathrm{TiOSO}_{4}$ structure, as well as the labeling scheme for the non-equivalent atoms are depicted in Figure 1. Such a representation provide a side-on view of the infinite -Ti-Ozigzag chains along the b-direction, which is a very distinctive feature of this structure.

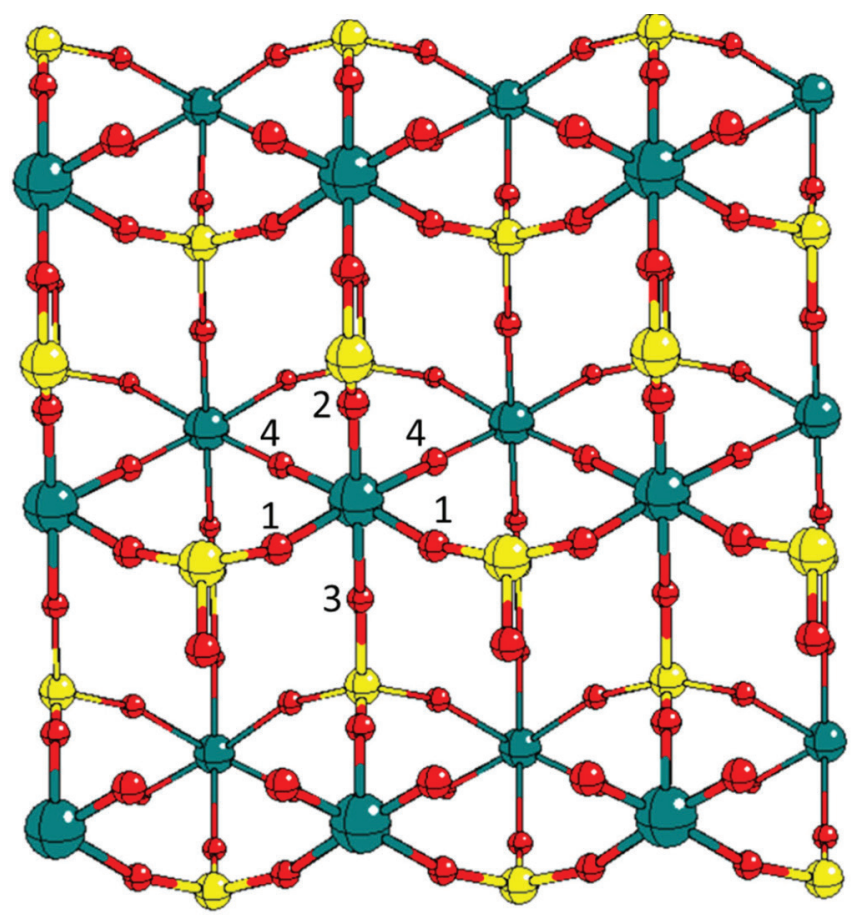

Figure 1. Crystallographic structure of the titanium oxide sulfate $\mathrm{TiOSO}_{4}$ viewed down the $c$ axis, showing atom numbering. Green, red and yellow spheres represent the Ti, O e S atoms, respectively

Optimizations were carried out starting from experimental data given by Ahmed and co-workers. ${ }^{13}$ The optimized parameters for $\mathrm{TiOSO}_{4}$ bulk are as follow: $\mathrm{a}=11.160 \AA, \mathrm{b}=5.264 \AA$ and $\mathrm{c}=6.607 \AA$, which are in good agreement with experimental data, namely, $10.953 \AA, 5.152 \AA$ and $6.426 \AA$, respectively. The main bonding distances are presented in Table 1 . Both the titanium and sulfur atoms are at sites $4 \mathrm{c}$ (corresponding to the Wickof notation reflection operation) according to Ahmed et al. ${ }^{13}$ The calculation did not alter these local symmetries.

Table 1. Calculated interatomic distances, in $\AA$, for the crystal structure of $\mathrm{TiOSO}_{4}$

\begin{tabular}{cccccc}
\hline & Calc. & Exp. $^{13}$ & & Calc. & Exp. $^{13}$ \\
\hline $\mathrm{Ti}-\mathrm{O}(1) \times 2$ & 2.095 & 2.014 & $\mathrm{~S}-\mathrm{O}(4) \times 2$ & 1.489 & 1.474 \\
$\mathrm{Ti}-\mathrm{O}(2)$ & 1.964 & 1.876 & $\mathrm{~S}-\mathrm{O}(2)$ & 1.506 & 1.496 \\
$\mathrm{Ti}-\mathrm{O}(3)$ & 1.986 & 1.944 & $\mathrm{~S}-\mathrm{O}(3)$ & 1.506 & 1.443 \\
$\mathrm{Ti}-\mathrm{O}(4) \times 2$ & 1.789 & 1.786 & & & \\
\hline
\end{tabular}

\section{Vibrational Spectroscopy}

Figure 2 shows the Raman and infrared spectra for $\mathrm{TiOSO}_{4}$.

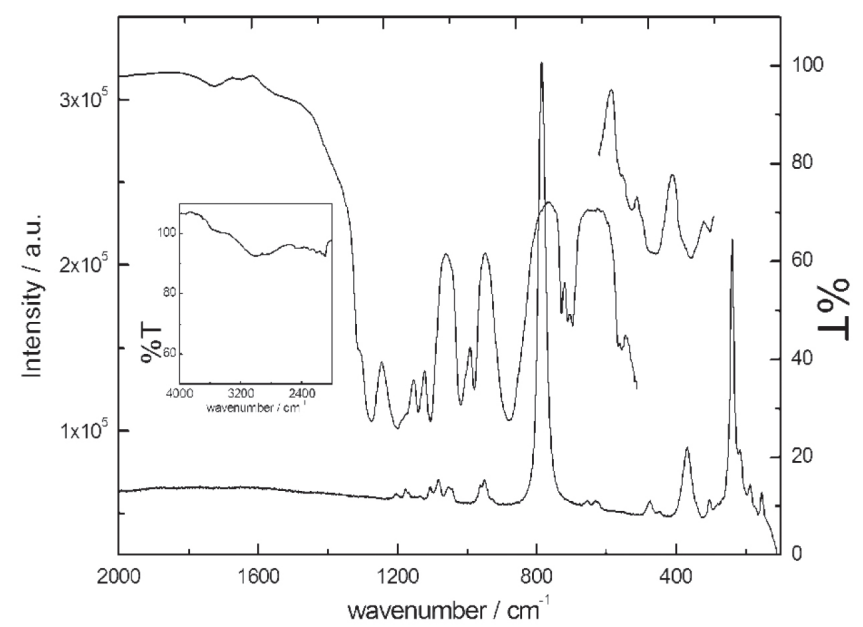

Figure 2. Infrared, far infrared and Raman spectra $(632,8 \mathrm{~nm})$ of solid TiOSO

From the Raman and IR spectra, it is observed that there is practically no coincidence of bands, indicating the presence of symmetry center, as indicated by the crystallographic data and confirmed by the calculation of the structure. The extensive splitting of sulfate bands indicates a lower symmetry than that of the free sulfate, due to the coordination with the titanium ion, as well as due to the lower local symmetry where the sulfate anion is found. In this case, the sulfate anion occupies a position (4c), which corresponds to the presence of a plane of symmetry. This low symmetry causes the splitting of all sulfate degenerate modes. The correlation and the factor group methods can be invoked to explain the high number of observed bands, since the number of sub-units in the unit cell $(\mathrm{Z}=4)$ produce several combinations of normal modes inside the unit cell. The Raman spectrum is quite peculiar, showing two intense bands at 239 and $785 \mathrm{~cm}^{-1}$, in addition to a weaker band at $368 \mathrm{~cm}^{-1}$, the other bands being quite weak. No Raman bands are observed in the $1600 \mathrm{~cm}^{-1}$ region, indicating water absence.

The general appearance resembles the Raman spectrum of a coordinated sulfate anion, with several splitted modes, plus bands that may be tentatively assigned to the $\left[\mathrm{TiO}_{6}\right]$ backbone modes. It is important to point out that a reasonable interpretation model should be based on the vibrational modes of both $\left[\mathrm{TiO}_{6}\right]$ and $\left[\mathrm{SO}_{4}{ }^{2-}\right]$ moieties. The expected vibrational representation for octahedral $\left[\mathrm{TiO}_{6}\right]$ is $\Gamma=\mathrm{A}_{1 \mathrm{~g}}$ 
(Raman, stretching $)+\mathrm{E}_{\mathrm{g}}($ Raman, stretching $)+\mathrm{T}_{1 \mathrm{u}}(\mathrm{IR}$, stretching $)+$ $\mathrm{T}_{1 \mathrm{u}}$ (IR, bending) $+\mathrm{T}_{2 \mathrm{~g}}$ (Raman, bending) $+\mathrm{T}_{2 \mathrm{u}}$ (inactive, bending); disregarding the splittings, it would be expected three Raman and two infrared bands. Bendings are expectd below $400 \mathrm{~cm}^{-1}$ and stretchings, above $400 \mathrm{~cm}^{-1}$. For the $\left[\mathrm{SO}_{4}{ }^{2-}\right]$ group, is expected the usual pattern for a tetrahedral $\mathrm{XO}_{4}$, for instance, $\Gamma=\mathrm{A}_{1}$ (Raman, stretching) + $\mathrm{E}$ (Raman, bending $)+\mathrm{T}_{2}$ (IR, stretching $)+\mathrm{T}_{2}$ (IR, bending)

Table 2 shows the experimental infrared and Raman wavenumbers.

Table 2. Experimental infrared and Raman wavenumbers $\left(\mathrm{cm}^{-1}\right)$, with tentative assignment (see text), for $\mathrm{TiOSO}_{4}$

\begin{tabular}{|c|c|c|}
\hline IR & Raman & Assignment \\
\hline & 154(w) & \\
\hline & 187(w) & lattice modes \\
\hline \multicolumn{3}{|l|}{$211(\mathrm{vw})$} \\
\hline & $239(s)$ & \\
\hline \multicolumn{3}{|l|}{$269(\mathrm{~m})$} \\
\hline \multicolumn{3}{|l|}{$295(\mathrm{sh})$} \\
\hline & 304(vw) & \multirow{6}{*}{$\delta \mathrm{TiO}_{6}$ modes } \\
\hline & $368(\mathrm{~m})$ & \\
\hline \multicolumn{2}{|l|}{$373(\mathrm{~m})$} & \\
\hline \multicolumn{2}{|l|}{$387(\mathrm{~m})$} & \\
\hline \multicolumn{2}{|l|}{$418(\mathrm{sh})$} & \\
\hline \multirow{2}{*}{\multicolumn{3}{|c|}{$446(w)$}} \\
\hline & & \\
\hline $478(w)$ & & $\mathrm{v}_{2}\left(\mathrm{SO}_{4}{ }^{2-}\right)$ \\
\hline \multicolumn{3}{|l|}{$490(w)$} \\
\hline & $628(\mathrm{vw})$ & \\
\hline \multicolumn{3}{|l|}{$629(\mathrm{~m})$} \\
\hline \multirow[t]{2}{*}{$642(\mathrm{~m})$} & & $\mathrm{V}_{4}\left(\mathrm{SO}_{4}^{2-}\right)$ \\
\hline & 654(vw) & \\
\hline \multicolumn{3}{|l|}{$661(\mathrm{~m})$} \\
\hline & $785(\mathrm{vs})$ & $v(\mathrm{Ti}-\mathrm{O}) \mathrm{s}$ \\
\hline $819(\mathrm{~s}, \mathrm{br})$ & & $v(\mathrm{Ti}-\mathrm{O})$ \\
\hline \multicolumn{3}{|l|}{$925(\mathrm{~m})$} \\
\hline & 949(w) & \multirow{2}{*}{$v_{1}\left(\mathrm{SO}_{4}^{2-}\right)$} \\
\hline & $961(w)$ & \\
\hline \multicolumn{3}{|l|}{$967(s)$} \\
\hline & 1044(w) & \multirow{12}{*}{$\mathrm{v}_{3}\left(\mathrm{SO}_{4}{ }^{2-}\right)$} \\
\hline & 1053(w) & \\
\hline \multicolumn{3}{|l|}{ 1059(m) } \\
\hline & 1081(w) & \\
\hline \multicolumn{3}{|l|}{ 1094(m) } \\
\hline & $1105(w)$ & \\
\hline & 1134(vw) & \\
\hline $1129(\mathrm{sh})$ & & \\
\hline \multirow[t]{4}{*}{$1156(\mathrm{~m})$} & & \\
\hline & $1169(\mathrm{vw})$ & \\
\hline & 1176(wv) & \\
\hline & $1203(\mathrm{vw})$ & \\
\hline \multirow{2}{*}{\multicolumn{2}{|c|}{$\begin{array}{l}1236(\mathrm{~m}) \\
1277(\mathrm{sh}) \\
\end{array}$}} & \\
\hline & & \\
\hline \multicolumn{3}{|l|}{$1715(\mathrm{vw})$} \\
\hline \multicolumn{3}{|l|}{ 2092(w) } \\
\hline 2131(vw) & & combination bands \\
\hline \multicolumn{3}{|l|}{$2209(w)$} \\
\hline \multicolumn{3}{|l|}{$2467(\mathrm{vw})$} \\
\hline 2966(w,br) & & adsorbed water \\
\hline
\end{tabular}

In order to find out which bands in the Raman spectrum should be assigned to the $\left[\mathrm{TiO}_{6}\right]$ skeleton, it is enough to identify the ones due to the $\left[\mathrm{SO}_{4}{ }^{2-}\right]$ group, whose wavenumber modes do not vary significantly, when compared with other compounds containing this anion. The remaining bands can then be assigned to the $\left[\mathrm{TiO}_{6}\right]$ moiety. However, it should be remembered that lattice modes involving translations and librations of the $\left[\mathrm{SO}_{4}{ }^{2-}\right]$ and $\left[\mathrm{TiO}_{6}\right]$ groups are expected in the low wavenumber region. The band at $368 \mathrm{~cm}^{-1}$ is in the borderline between lattice and $\left[\mathrm{TiO}_{6}\right]$ angular deformation modes. The intense band at $785 \mathrm{~cm}^{-1}$ was tentatively assigned to totally symmetric stretching mode of this group. Such an assignment takes into account the following arguments: (i) the high intensity of this band should be probably due to metal-oxygen bond higher polarizability and its totally symmetric nature; (ii) the observed wavenumber value is close to that reported for other compounds containing Ti-O bonding, with a bond order less than $2{ }^{23,24}$ In the infrared spectrum, the band at 819 $\mathrm{cm}^{-1}$ is also tentatively assigned to a $v(\mathrm{Ti}-\mathrm{O})$ stretching mode. The medium bands at 925 and $967 \mathrm{~cm}^{-1}$ in the infrared spectra, as well as the weak Raman bands at 949 and $961 \mathrm{~cm}^{-1}$, although initially assignable to $\mathrm{v}_{1}\left(\mathrm{SO}_{4}{ }^{2-}\right)$, may have some contribution from $v(\mathrm{Ti}-\mathrm{O})$ stretching modes. ${ }^{25}$ The justification for this would be as follows. In some compounds, where the titanium ion is connected to a single oxygen atom, forming a true $\mathrm{Ti}=\mathrm{O}$ bond, a single vibrational mode is expected, occurring at highest wavenumbers, near $950 \mathrm{~cm}^{-1} .^{4-11} \mathrm{In}$ the $\mathrm{TiOSO}_{4}$ crystal structure, there is a short Ti-O bond (Ti-O(4), $1.786 \AA$ ), whose character may be considered to be intermediate between a single and a double bond [compare with $1.62 \AA$ for $\mathrm{TiO}$ (porphyrin)]..$^{5}$ Assuming these Ti-O bonds behave as individual oscillators, bands with a wavenumber greater than $900 \mathrm{~cm}^{-1}$ could be assigned to $\mathrm{v}(\mathrm{Ti}-\mathrm{O})$ stretching modes involving shorter Ti-O bonds, such as the Ti-O(4) bond. Moreover, another argument to consider is the fact that the oxygen atom of this shorter Ti-O(4) bond is just that belonging to the $\left[\mathrm{SO}_{4}{ }^{2-}\right]$ group. Thus, the presence of a mechanical coupling between the $v(\mathrm{Ti}-\mathrm{O})$ stretching involving the Ti-O(4) bond and the $\mathrm{v}_{1}\left(\mathrm{SO}_{4}{ }^{2-}\right)$ may be considered. These arguments justify the presence of some $\mathrm{v}(\mathrm{Ti}-\mathrm{O})$ character in the vibrational modes assigned to $v_{1}\left(\mathrm{SO}_{4}^{2-}\right)$; this could explain the relatively high intensity observed in the infrared spectra for $v_{1}$ totally symmetric mode together with reduced local symmetry effects that make it infrared active. However, an exact and quantitative description of the normal modes requires a normal coordinate calculation, either by the classical or by ab initio methods; this problem is currently being investigated in our group using using the CRYSTAL17 capabilities. Preliminary results indicate extensive normal mode mixing involving the two moieties.

Similarly to the Raman spectrum, the infrared spectrum essentially shows the splitted $\left[\mathrm{SO}_{4}{ }^{2-}\right]$ group modes, with, as already mentioned, an extra band at $819 \mathrm{~cm}^{-1}$, assigned to a $v(\mathrm{Ti}-\mathrm{O})$ stretching mode. It should be remembered that this value is lower than that observed in titanium compounds with $\mathrm{Ti}=\mathrm{O}$ double bond $\left(\mathrm{ca} .950 \mathrm{~cm}^{-1}\right)$. The splitting pattern resembles that of the sulfated $\mathrm{TiO}_{2},{ }^{26-28}$ mainly in the $\mathrm{v}_{4}\left(\mathrm{SO}_{2}{ }_{2}\right)$ region, in the range of 1050 to $1200 \mathrm{~cm}^{-1}$. An important evidence that the compound analyzed is really the anhydrous $\mathrm{TiOSO}_{4}$ is the absence of the angular deformation mode of water at ca. $1600 \mathrm{~cm}^{-1}$, as was also observed in the Raman spectrum. However, there is a weak and broad band seen at $2966 \mathrm{~cm}^{-1}$. It has a somewhat low wavenumber to be assigned to adsorbed water; the presence of some reticular water should be considered. The low wavenumber may indicate a very intense hydrogen bond. In this situation, there is usually a large increase in intensity due to increased anharmonicity. In this way, despite the apparent intensity, the amount of water must be small. The bands in the $2000-2500 \mathrm{~cm}^{-1}$ can be assigned to combination or harmonic bands. Another important point is that the number of expected modes (from correlation or factor group method) 
is usually much higher than the observed ones, which is certainly due to low-intensity modes and accidental degeneracy.

\section{CONCLUSIONS}

From the experimental Raman and infrared spectra, it was possible to verify that mutual Raman/infrared exclusion rule is operative and allows confirming that the crystalline structure is centrossimetric, which favors Pnma symmetry, instead of Pna2 $2_{1}$. Strong Raman bands were assigned to lattice modes and $v_{\mathrm{s}}(\mathrm{Ti}-\mathrm{O})$. The geometry optimization calculations employing CRYSTAL17 were satisfactory, taking into account the calculated/experimental concordance. This seeds the basis for additional calculations involving vibrational wavenumbers, which will be useful for confirming the proposed assignment.

\section{ACKNOWLEGEMENTS}

The authors are grateful to LEM (IQUSP, São Paulo) for the far infrared spectra on Bomem DA3.16 and to FAPESP (process 2017/06194-2) for the financial support.

\section{REFERENCES}

1. Hadjiivanov, K. I.; Klissurski, D. G.; Chem. Soc. Rev. 1996, 25, 61.

2. Noda, L. K.; Rosales, R.; Gonçalves, N. S.; Sala, O.; J. Raman Spectrosc. 2008, 39, 415.

3. Gonçalves, N. S., Rettori, D., Silva, G. M. G., Noda, L. K.; Vib. Spectrosc. 2018, 99, 80.

4. Gratzel, M.; Rotzinger, F. P.; Inorg. Chem. 1985, 24, 2320.

5. Dwyer, P. N.; Puppe, L.; Buchler, J. W.; Scheidt, W. R.; Inorg.Chem. 1975, 14, 1782.

6. Taube, R.; Z. Chem. 1963, 3, 194.

7. Block, B. P.; Meloni, E. G.; Inorg.Chem. 1965, 4, 111.

8. Feltz, A.; Z. Chem. 1967, 7, 158

9. Kristine, F. J.; Shepherd, R. E.; Siddiqui, S.; Inorg. Chem. 1981, 20, 257.
10. Dehnicke, K.; Pausewang, G.; Rüdorff, W.; Z. Anorg. Allg. Chem. 1969, 366, 64.

11. Comba, P.; Merbach, A.; Inorg. Chem. 1987, 26, 1315.

12. Clark, R. J. H.; Bradley, D. C.; Thornton P.; Pergamon Texts in Inorganic Chemistry 1973, 19, 377.

13. Ahmed, M. A. K.; Fjellvag, H.; Kjekshus, A.; Acta Chem. Scand. 1996, 50,275

14. Reynolds, M. L.; Wiseman, T. J.; J. Inorg. Nucl. Chem. 1967, 29, 1381.

15. Dovesi, R.; Erba, A.; Orlando, R.; Zicovich-Wilson, C. M.; Civalleri, B.; Maschio, L.; Rerat, M.; Casassa, S.; Baima, J.; Salustro, S.; Kirtman, B.; Wiley Interdiscip. Rev.: Comput. Mol. Sci. 2018, 8, e1360.

16. Perdew, J. P.; Ruzsinszky, A.; Csonka, G. I.; Vydrov, O. A.; Scuseria, G. E.; Constantin, L. A.; Zhou, X. L.; Burke, K.; Phys. Rev. Lett. 2008, 100, 136406.

17. Mackrodt, W. C.; Simson, E. A.; Harrison, N. M.; Surf. Sci. 1997, 384, 192.

18. Bredow, T.; Heitjans, P.; Wilkening, M.; Phys. Rev. B 2004, 70, 115111.

19. Cora, F.; Mol. Phys. 2005, 103, 2483.

20. http://www.crystal.unito.it/basis-sets.php, accessed September 2019.

21. Ugliengo, P.; MOLDRAW: A program to display and manipulate molecular and crystal structures, Torino, 2006, available at http://www. moldraw.unito.it.

22. Ugliengo, P.; Viterbo, D.; Chiari, G.; Z. Kristallogr. 1993, 207, 9.

23. van de Velde, G. M. H.; Harkema, S.; Gellings, P. J.; Inorg. Nucl. Chem. Lett. 1973, 9, 1169

24. Barraclough, C. G.; Lewis, J.; Nyholm, R. S.; J. Chem. Soc. 1959, 3552.

25. Bragina, M. I.; Tsevtkova, M. P.; Bobyrenko, Y. Y.; Rus. J. Phys. Chem. 1977, 51, 720 .

26. Noda, L. K.; de Almeida, R. M.; Gonçalves, N. S.; Probst, L. F. D.; Sala, O.; Catal. Today 2003, 85, 69.

27. Noda, L. K.; de Almeida, R. M.; Probst, L. F. D.; Gonçalves, N. S.; J. Mol. Catal. A: Chem. 2005, 225, 39.

28. de Almeida, R. M.; Noda, L. K.; Gonçalves, N. S.; Meneghetti, S. M. P.; Meneghetti, M. R.; Appl.Catal., A 2008, 347, 100.

FAPESP helped in meeting the publication costs of the article 